\title{
The Mechanism for Introduction of Strategic Talents to Less-Developed Areas: An Analysis from the Perspective of Collaborative Governance Theory
}

\author{
Yihe Cai \\ Graduate School of Government, Beijing Normal University, Beijing, China \\ Email: caiyihe@yeah.net
}

How to cite this paper: Cai, Y.H. (2018) The Mechanism for Introduction of Strategic Talents to Less-Developed Areas: An Analysis from the Perspective of Collaborative Governance Theory. Open Journal of Business and Management, 6, 963-972. https://doi.org/10.4236/ojbm.2018.64071

Received: September 15, 2018

Accepted: October 26, 2018

Published: October 29, 2018

Copyright $\odot 2018$ by author and Scientific Research Publishing Inc. This work is licensed under the Creative Commons Attribution International License (CC BY 4.0).

http://creativecommons.org/licenses/by/4.0/ (c) (i) Open Access

\begin{abstract}
In the era of knowledge economy, the introduction of strategic talents plays an important role in achieving rapid economic development of less-developed areas. However, due to the "Matthew effect", there is high degree of polarization in the field of strategic talent introduction which is riddled with many other issues as well, and it is difficult to solve so many problems simply by relying on the government and the self-developed solutions of the companies. The collaborative governance which emerged as a new social theory in response to the needs of modern society can be used as a theoretical basis for the participation of government, market and the society. From the perspective of collective governance, this paper aims to identify through case study the main problems in the strategic talent introduction mechanism of less-developed areas, explore the collaborative governance model of the same and draw some inspiration from such a model so as to propose possible solutions.
\end{abstract}

\section{Keywords}

Strategic Talent Introduction Mechanism, Less-Developed Areas,

Collaborative Governance

\section{Background}

\subsection{Introduction}

Since the reform and opening up, the route of development that China has been pursuing has been encouraged some areas that have advantages in terms of loca- 
tion, resources, talents, and policies to develop first, and such first developed-areas will then help drive the development of less-developed areas and eventually achieve common prosperity. However, in order to achieve higher returns faster, most of the resources always flow to more mature areas and drive the economic development of the same, causing increasingly higher degree of regional disparity. In order to truly narrow the gap between the less-developed areas and the first-developed regions, the most fundamental method is to cultivate and attract talents, and it is necessary to treat the introduction of talents, especially strategic talents, as a development strategy. However, due to the existence of the "Matthew effect", the more resource-rich regions always attract more talents; and resource-poor areas are more likely to lose more talents. It is difficult to solve such a dilemma simply by relying on self-improvement of the enterprises and government policies. From the perspective of collective governance theory, this paper aims to provide an in-depth discussion of the role of the government, main market players (enterprises) and social organizations in the strategic talent introduction, so as to find out the problems in the strategic talent introduction of less-developed areas and attempt to construct a strategic talent introduction mechanism with collaborative governance.

\subsection{Definitions of Related Concepts}

\subsubsection{Less-Developed Areas}

The term "less-developed areas" is a focused area of study in regional economics [1]. Less-developed areas refer to areas that sit between economically developed regions and economically underdeveloped regions, which have completed preparations for accelerated development and are at an important junction in development. It is an extremely efficient research subject in the field of regional economics study. The concept of "less-developed area" is not only a geographical concept, but also a concept of administrative divisions and the level of economic development. Its research boundary involves all aspects of economy, population, resources and environment, social system and so on. It is precisely because of the comprehensiveness and extensiveness of its research content that the theoretical circles at home and abroad have not yet formed an authoritative and clear definition of the boundary and connotation of this concept, but still remain at the stage of abstract description. The Western theories developed for study in this field first stated that the emergence of regional imbalances and less-developed areas is a historical fact that cannot be violated, then, such studies focused on explaining how can the less-developed areas overcome their own disadvantages, and exert their unique advantages as the "followers" to create a unique development model for catching up with the first development areas. In view of the imbalance of China's regional development and other issues, some domestic scholars have also defined the concept and connotation of the late-developing areas in terms of space and characteristics, such as Wu Youde's "theory of economic growth in undeveloped regions" [2], Hou Jingxin's "general theory of development in backward regions" [3], and Li Qing's "advantage of backwardness: Chi- 
na's underdeveloped regions" [4]. There are different expressions in the study of regional development transformation [5].

\subsubsection{Strategic Talents}

Talents refer to persons who have certain professional knowledge or expertise, are capable of creative work and contributing to society, meaning laborers with higher ability and quality than average ones. Strategic talents can be defined as those who have certain knowledge, skills and abilities, can carry out creative work, and make greater contributions to the implementation of organizational planning and the realization of organizational mission. The theoretical basis of strategic talent research is mainly the talent science established by Chinese scholars. It also accepts and draws lessons from the basic ideas and main viewpoints of strategic management science and strategic human resource management science [6].

As the largest developing country in the world, China has a large population, a weak foundation, and relatively insufficient per capita resources. Such basic national condition determines that China's development must be "people-oriented" and adhere to the principle of revitalization through talents development. To this end, China has launched corresponding national strategy, regards talents as a key factor in promoting the development of the country, and strives to create hundreds of millions of high-quality laborers, tens of millions of specialized talents and a large number of top-notch innovative talents, build a reasonable talent structure of huge scale and high quality, create a new situation in which talented people come out and make the best use of their talents, transform China from a populous country into a country with strong talent resources, with vigorously enhanced core competitiveness and overall national strength, so as to complete the historical task of building a well-off society in an all-round way and realize the great rejuvenation of the Chinese nation. China's talent strategy is an important part of its economic and social development strategy, and reflects the overall planning and thinking about its development of human resources.

The concept of strategic talent is derived from the talent strategy and puts higher demands on talents involved. Strategic talents need to have multiple capabilities: including strategic and innovative thinking, predictive capabilities (for future changes), strategic implementation and design, decisive decision-making, ability to communicate with others, visions as well as noble personality and appeal.

\section{Review and Practical Values of the Collaborative Governance Theory}

The concept of collaborative governance comes from collaborative management. The collaborative governance theory is about how to effectively achieve the overall functional effects of the system by using collaborative thinking and methods to summarize the rules about management objects and implement management of the same [7]. Realizing synergy is the goal of collaborative manage- 
ment, the intrinsic nature of which is that the elements will produce relevant order parameters in the process of interacting with each other in a certain way, promoting the system to develop in an orderly and stable fashion and maximizing the effect of overall function of the system [8].

The study of collaborative governance by foreign scholars began in 1976 with the introduction of Synergic theory by Haken, a German physicist [9], which stated that under certain conditions, both the non-equilibrium state and the equilibrium state can complete the transition from disorder to order, and completely different subsystems can constitute a new system. Synergic theoryis formed by the development of completely different systems, which states that, no matter what kind of evolution occurs, subsystems will always interact and coordinate with each other to arrive at orderly results [10].

Inspired by the Synergic theory, some western scholars introduced the same into sociology and began to study social collaborative governance, which has led to the development of the theory of social collective governance. In 1995, the concept of collaborative governance was introduced to China and immediately became a popular theory among domestic scholars, when China entered a new era of market economy development. In the 1990s, the traditional government only management model can no longer meet the needs of society for public services. On the other hand, diverse entities such as social organizations, markets, and citizens are becoming eager to participate in social management. As such, it is required to develop a new management philosophy to promote the transformation of the government's management model, and gradually shift the same to a collective governance model with multiple subjects. As a result, new theoretical concepts such as multi-governance, multi-center governance, and cooperative governance have emerged and become the theoretical basis and source of collaborative governance theories. In 2004, the Fourth Plenary Session of the 16th CPC Central Committee proposed for the first time "to establish and improve a new pattern of social management with party committee leadership, government responsibility, social coordination, and citizen participation". The collaborative governance research is on the right track under the guidance of national policies. The report of the 18th China National Congress pointed out that it is necessary to accelerate the reform of the social system. In addition to the original social management pattern with party committee leadership, government responsibility, social coordination, and citizen participation, China also attaches importance to the "law guarantee" and aims to establish a "modern social organization system with separated political and social elements, clear powers and responsibilities and legal autonomy". Under the development direction stated above, China will further extend its research on collaborative governance to meet new development requirements [11].

In the past two decades, the collaborative governance research in China has been continuously enriched in contents and diversified in directions. Specifically, such research can be divided into the following aspects: First, the research on the theory of collective governance itself has been conducted to explore the 
background of its emergence and its definition, characteristics and practical significance. Second, the study of collaborative governance in government transformation has been conducted to determine that collaborative governance is an inevitable trend in the development of government governance models. Third, research has been conducted on the collaborative governance of public service provision. The Third Plenary Session of the Seventeenth Central Committee of the Party puts forward the goal of "equalization of public service provision", which promoted the study of public service supply mechanisms in collaborative governance research. Fourth, research has been conducted on the collaborative governance of government and social organizations. In the "16-character" new social management pattern proposed by the Fourth Plenary Session of the 16th Central Committee, "social cooperation" has become the new focus of collaborative governance. Fifth, a reflection on the collaborative governance theory itself is also a must do. Through practice, scholars can and will constantly revise, broaden and deepen the research on collaborative governance research.

Besides, in terms of theoretical definition, domestic scholars generally adopt the following two ways. Firstly, "synergy governance = synergy theory + governance theory". For example, Zheng Qiao and Xiao Wentao believe that "based on the theory of synergetics and governance theory, synergetic governance refers to the process of public life, between the main to safeguard and promote public interest for the purpose" [12]. As Cai Yandong pointed out, "Based on the theory of synergetics, the theory of synergetic governance refers to the harmonious, orderly and efficient public governance network formed in the process of public life" [13]. Secondly, borrow the definition given by international organizations. As Liu Weizhong borrowed the definition given by the UN Global Governance Committee: "Collaborative governance is an ongoing process". It includes both formal and legally binding systems and rules, as well as informal institutional arrangements for consultation and reconciliation [14]. Li Hui and Ren Xiaochun also believe that the concept given by the UN Global Governance Committee is highly recognized [15].

\section{Problems with the Current Talent Introduction Process of the Less-Developed Areas}

Less-developed areas tend to have relatively weaker social economy and imperfect operating mechanisms. In the case of handling matters of strategic talent introduction, these areas tend to rely solely on either the government or the market, inevitably going to the two extremes as both the market and the government may encounter difficulties that cannot be avoided in the process of strategic talent introduction when they are faced with some temptations such as chances to evade responsibilities and taking a free ride [16].

\subsection{Government-Only Governance Can Not Solve the Problems of Strategic Talent Introduction}

Government policies and related mechanisms play a major role in regional eco- 
nomic development, especially in less-developed areas where government mechanisms exert overwhelming influence. However, the government cannot solve all problems. With the further development of the social economy and due to the existence of the "Matthew effect", the reliance on government-only governance has led to an increasing number of problems during strategic talent introduction.

First, the government actions may fail. As ordinary persons in real life, government officials will also pursue personal goals and maximize personal interests. Their actions may not necessarily meet public interest or social collective goals at some point. First of all, in order to achieve political achievements, the government tends to focus too much on large-scale projects with more funds, while ignoring those that can help promote the development of talent resources, especially strategic talents with strategic long-term thinking. Secondly, due to asymmetry of information, the government may not be able to accurately calculate the full cost and benefits of the strategic talent introduction, making it difficult to make an accurate assessment. Thirdly, the highly rigid and bureaucratic style of government decision-making may affect the rational allocation of strategic talent resources. Lastly, government policies may change frequently, casuing disruption to the production and management activities of enterprises, in which case a stable environment required for strategic talents to achieve their values is nonexistence even when such talents are introduced.

Second, there is a lack of communication between government and enterprises. Less-developed areas are mainly rely on political and economic preferential policies to attract talents without paying attention to the construction of cooperative development mechanisms for human resources, and the participation of enterprises, universities, scientific research institutions, and social organizations in the development and utilization of strategic talents. Such a phenomenon will lead to a series of problems, including neglecting the quality of strategic talents and the importance of establishing a stable environment for talent growth; poor follow-up services.

\subsection{Market Mechanism Defects in Less-Developed Areas}

The market mechanism is at the core of strategic talent introduction to less-developed areas. However, due to market failures and high cost of strategic talents, it is difficult to make adjustments only through the market, which requires support from the government.

First, enterprises in the less-developed areas lack vitality. Less-developed areas have weaker economic bases. Most enterprises in these areas are SMEs that are more likely to be concerned by factors such as the cost of development. Due to the small scale of the companies, if the introduction of strategic talents by themselves may not be economical, as a result they lack the enthusiasm to do so. If government and social forces can be utilized to promote multi-party participation in the strategic talent introduction, it is possible to receive guidance on strategic talent introduction and reduce the costs of the same. At the same time, 
the process of absorbing strategic talents is also a process for enterprises to comprehensively study human resource management, which can help promote the growth of SMEs.

Second, public services in less-developed areas are not sufficiently market-oriented. When choosing a career, talents, especially strategic talents, will inevitably consider how much added value the working and living areas can bring to themselves in addition to the strengths and weaknesses of the enterprise itself, so the quality of public service in the region where the enterprise is located is an important factor affecting the strategic talent introduction. Due to the long-term influence of the planned economic system, the less-developed areas often have less-developed public service supply mechanisms, with some public service matters related to people's livelihood being handled only by the government, leading to increased government pressure as well as reduced quality and efficiency of public services.

\subsection{Social Organizations and Citizens Are Less Motivated to Participate}

The "bureaucracy nature" phenomenon is still relatively rampant in China, especially in less-developed areas where the relatively low level of knowledge and consciousness among citizens and social organizations has impeded their participation in public affairs as well as the enthusiasm to do so. Citizens and social organizations often mistakenly believe that only government departments shall be responsible for public services. As a result, they rely on the government for public service affairs, act passively and are less motivated to participate. Due to the government's arbitrariness in public services and lack of systemicity and continuity, the government as a provider tends to focus on the construction of large-scale economic infrastructure, leaving only insufficient investment in public services (such as social security, science and technology culture, and environmental protection) that affect the flow of talents.

In short, institutional innovation is required in order to get out of the current predicament.

\section{The Significance of Collaborative Governance Theory to the Strategic Talent Introduction of Less-Developed Areas}

Strategic talent introduction is the key to achieving leap-forward development in less-developed areas and it is closely related to the fundamental interests of all members of society (including enterprises and individuals) throughout the region. Collaborative governance emphasizes participation by multiple governance entities including government, social organizations, corporates and citizens, the ability to calculate costs and benefits and promote profit expansion; at the same time, it also encourages all subjects to abide by the code of conduct, effectively manage public affairs through cooperative interaction, and achieve optimal resource allocation [17].

Therefore, using the theory of multi-center collaborative governance, we can 
fully utilize the effectiveness of collaborative governance in the integration of strategic talent resources and provide operational ideas for solving the issues in talent introduction of less-developed areas by building a multi-dimensional interaction model (government, market and social organizations) for strategic talent introduction activities.

\section{Course of Action in the Strategic Talent Introduction of Less-Developed Areas}

The introduction of strategic talents to less-developed areas shall follow the theory of collective governance, including collaborative governance with multiple entities (government departments, enterprises and social organizations), promotion and improvement of the strategic talent introduction mechanism through market-oriented approach, social participation, and legalization guarantee etc. (Figure 1) [18]

1) Promote the market-oriented approach and give full play to the important carrier role of enterprises in the strategic talent introduction of less-developed areas

We shall promote changes in the role of government in the strategic talent introduction (from "operations" and "policies" to "regulation" and "environment") and further transform relevant government functions (from intervention

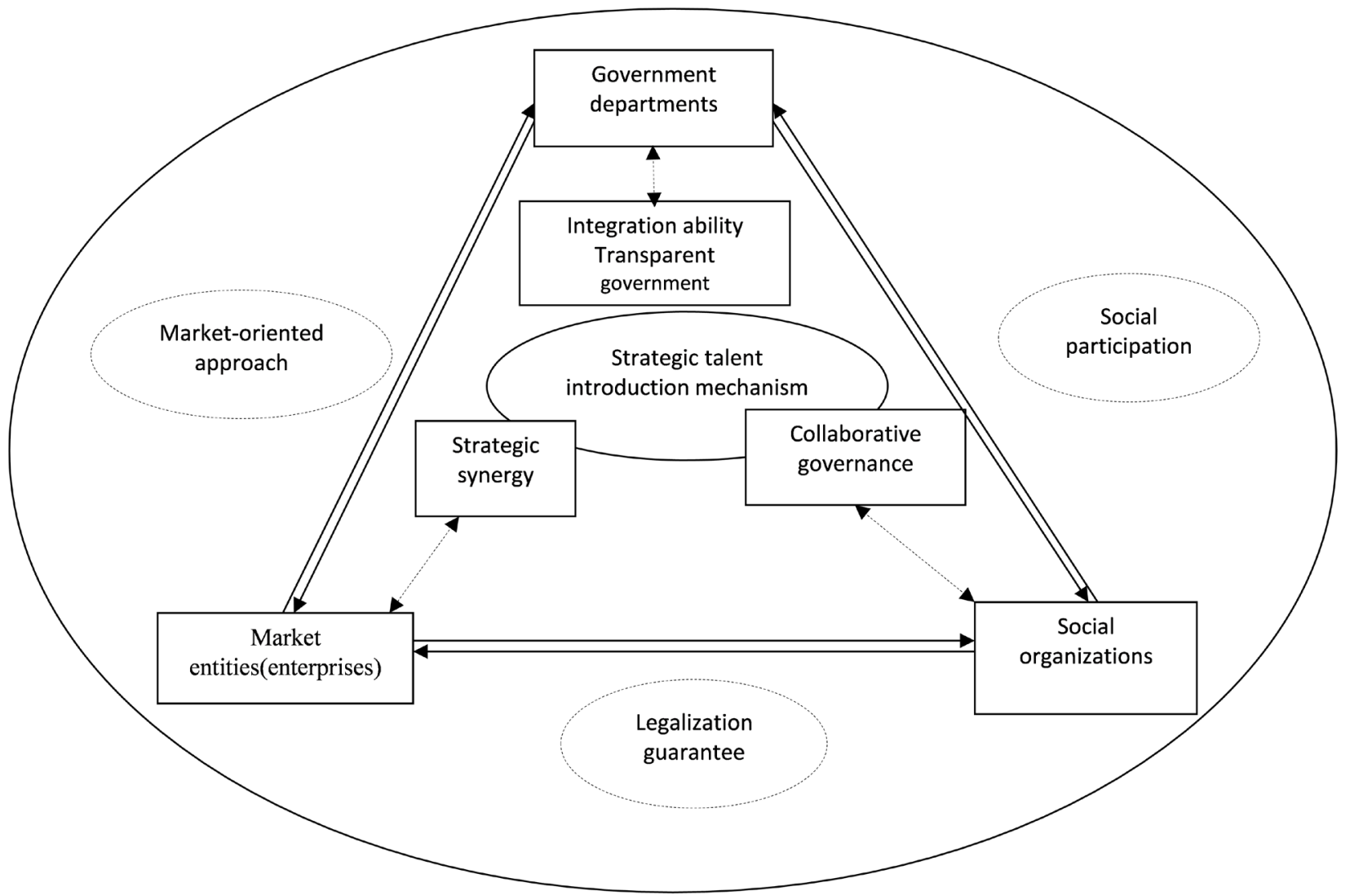

Figure 1. Framework diagram of the strategic talent introduction mechanism for less-developed areas [19]. 
to diversification). In particular, enterprises shall truly become important carriers of talent introduction works, overcoming the issues such administrative style and bureaucratic nature etc. in the current strategic talent introduction mechanism. It is required to use market and social forces to absorb strategic talents and create a market environment for talent development. Companies can advise the government during the strategic talent introduction process for the purpose of creating an HR development policy environment that suits them. At the same time, they shall also adopt different compensation strategies for different business strategies [20].

2) Break communication barriers and promote social participation

It is required to vigorously cultivate and support social organizations and third-party institutions, promote the vigorous development of various industries and service organizations, and the communication between government and enterprises [21]. By exploring the collective governance model with government departments related to strategic talent introduction and the public institutions, civil organizations, private institutions and other entities, and various forms of actions such as government procurement, service outsourcing, and collaborative development, we will be able to allow multiple entities to participate in public services related to the supply of strategic talents and increase the quantity and quality of service delivery of the same.

3) Establish legislation guarantee for the strategic talent introduction

By gradually strengthening the rule of law construction for talent introduction and establishing a complete legal and regulatory system with sufficient content and coordinated structure, we can achieve comprehensive legislation for strategic talent introduction and transform the policy advantage of the same into the rule of law advantage, therefore providing a rule of law guarantee for introduction of all talents.

\section{Conclusion}

In summary, to effectively solve the predicament faced by of less-developed areas in strategic talent introduction, it is necessary to start with the supply of public services by promoting benign interaction between government, market and social organizations. On the basis of above actions, we can establish a new countermeasure system for the strategic talent introduction of less-developed areas and a systematic strategic talent introduction model that incorporates the mechanism of collaborative governance.

\section{Conflicts of Interest}

The author declares no conflicts of interest regarding the publication of this paper.

\section{References}

[1] Chen, Y. (2013) Research on Government Behaviors in Social Management Innova- 
tion in Less-Developed Areas-Taking Shuyang County, Jiangsu Province as an Example. Master's Thesis, Huazhong Normal University, Wuhan, 11.

[2] Wu, Y.D. (2000) The Growth Theory of Under-Developing Regions. China Economy Press, Beijing.

[3] Hou, J.X. (1999) General Theory of Development in Underdeveloping Regions. China Light Industry Press, Beijing.

[4] Li, Q.J. (2000) Advantage of Backwardness: Study of Development Transition of China's Underdeveloping Regions. Economic and Management Press, Beijing.

[5] Lu, C.J. (2014) Definition of China's Less-Developed Areas and Low-Carbon Development Strategies. China Population Resources and Environment, 24, 30-37.

[6] Wang, J. (2014) Research Foundation and Developing Logic of Strategic Talents. China Human Resources Development, 21, 84-89.

[7] Bai, L.H. and Wang, X.J. (2009) Discussion on the Construction of Management Cooperation Mechanism Model. Journal of Systems Science, 17, 42-45

[8] Pan, K.L. and Bai, L.H. (2007) Systematic Thinking on Management Synergy Multiplier Effect. Journal of Systems Science, 15, 70-73.

[9] Xu, H.M. (2002) The Application of Chaos and Synergic Theories in China's Manufacturing Industry Organizations. Doctoral Thesis, Harbin Engineering University, Harbin.

[10] Zou, S.G., et al. (1987) System Science. Shanghai People's Publishing House, Shanghai.

[11] Lu, B. and Zhou, D.C. (2014) Review and Prospect of Domestic Research on Collaborative Governance. Administrative Forum, 21, 84-89.

[12] Zheng, Q. and Xiao, W.T. (2008) Collaborative Governance: The Governance Logic of Service-Oriented Government. China Administration, No. 7, 48-53.

[13] Cai, Y.D. (2011) Path Selection from Government Crisis Management to Coordinative Crisis Management. Contemporary Social Sciences Perspective, No. 11, 31-35.

[14] Liu, W.Z. (2012) Current Situation and Trend of Collaborative Governance in China. Urban Problems, No. 5, 81-85.

[15] Li, H. and Ren, X. (2010) Collaborative Governance in the Perspective of Good Governance. Science and Management, No. 6, 55-58.

[16] McGinnis, M. (2000) Multi-Center System and Local Public Economy. Translated by Mao Shoulong, Li Mei, Shanghai Sanlian Bookstore, Shanghai, 75-76.

[17] Xu, W. and Sun, Z. (2010) Multi-Center Governance: Deep Innovation of Grassroots Public Affairs Management-Taking Owner Autonomy as an Example. Weishi, No. 2, 82-85.

[18] Qiu, Z. (2015) Multiple Governance + Mechanism Innovation: Path Selection for Local Governance Capacity Improvement. Jianghai Journal, 6, 212-216.

[19] Sun, R. (2016) Discussion on Issues Related to the Reform of Talent Management System in China during the 13th Five-Year Plan Period. Journal of National School of Administration, 3, 30-34.

[20] Tian, K. (2015) Gold. Research on Foreign Governance Theory: Process and Controversy. Political Science Research, 6, 47-58.

[21] Dong, S. (2016) A Study on the Mechanism of Introducing Talents from the Perspective of Multi-center Governance. China Market, 20, 187-189. 